\title{
Perancangan Prototype Sistem Keamanan Parkir Otomatis Berbasis Radio Frequency Identification (RFID)
}

\author{
Rosmiati $^{1}$, Hidayatullah Pratama ${ }^{2}$, Nuraeni Arif ${ }^{3}$ \\ ${ }^{1,2,3}$ Program Studi Teknik Informatika \\ 1,2,3 Universitas Islam Makassar, J1.Perintis Kemerdekaan Km. 9 No. 29 Makassar \\ Email : rosmiati.dty@uim-makassar.ac.id ${ }^{1}$, dayat939339@gmail.com² \\ nuraeniarif4@gmail.com ${ }^{3}$
}

\begin{abstract}
ABSTRAK
Terjadinya kasus kehilangan kendaraan di wilayah kampus khususnya kendaraan roda dua dikarenakan oleh sistem pengawasan keluar masuk kendaraan yang masih menggunakan cara manual. Hal ini dapat mengganggu proses pembelajaran yang berjalan di kampus. Untuk meminimalisir terjadinya pencurian kendaraan dibutuhkan teknologi sistem keamanan parkir yang bekerja secara otomatis.

Prototype sistem keamanan parkir yang dirancang dalam penelitian ini menggunakan teknologi Radio Frequency Identifacation (RFID) yang terhubung dengan website. RFID ini berfungsi untuk mengidentifikasi pengunjung kampus. Metode identifikasi pada RFID ini menggunakan gelombang radio yang dapat mengirimkan data identitas objek secara nirkabel atau tanpa bantuan manusia. Prototype ini menggunakan RFID card, RFID reader, Sensor Ultrasonik HRC04, NodeMCU ESP32, Buzzer, Motor Servo, PHP, dan MYSQL.

Hasil dari penelitian ini berupa Prototype sistem keamanan parkir dengan menggunakan teknologi Radio Frequency Identification yang diharapkan dapat membantu petugas keamanan dalam mengawasi keamanan parkir di wilayah kampus.
\end{abstract}

Kata Kunci : Prototype, Sistem Keamanan Parkir, RFID

\section{ABSTRACT}

The occurrence of cases of vehicle loss in the campus area, especially twowheeled vehicles, is due to the vehicle entry and exit control system that still uses the manual method. This can interfere with the learning process that runs on campus. To minimize the occurrence of vehicle theft, parking security system technology is needed that works automatically.

The parking security system prototype designed in this study uses Radio Frequency Identification (RFID) technology which is connected to the website. This RFID serves to identify campus visitors. This identification method in RFID uses radio waves that can transmit object identity data wirelessly or without human assistance. This prototype uses an RFID card, RFID reader, Ultrasonic Sensor HRC04, NodeMCU ESP32, Buzzer, Servo Motor, PHP, and MYSQL.

The results of this study are a prototype parking security system using Radio Frequency Identification technology which is expected to assist security officers in supervising parking security in the campus area.

Keywords : Prototype, Parking Security System, RFID 


\section{PENDAHULUAN}

Salah satu hal yang sangat penting dikelola secara profesional dilingkungan kampus adalah sistem pengontrolan keamaan kendaraan. Hal ini dilakukan agar proses pembelajaran dapat berjalan dengan nyaman dan untuk mewujudkan lingkungan kampus yang aman tertib dan terkendali (Ketut et al., 2017). Sistem parkir di Universitas Islam Makassar saat ini masih menggunakan beberapa operator yang ditugaskan untuk menjalankan sistem parkir, dimana petugas parkir harus menggerakkan portal untuk membuka dan menutup akses lahan parkir (Uray Ristian, Weldi, 2020). Jika petugas keamanan lalai dalam mengawasi sistem parkir maka akan membuka peluang terjadinya pencurian kendaraan khususnya kendaraan roda dua.

Di zaman sekarang ini kemajuan teknologi terus berkembang dengan sangat pesat. Salah satunya adalah teknologi keamanan yang dapat di temui adalah pengontrol keamanan portal parkir. Hampir setiap tempat mempunyai teknologi keamanannya sendiri agar tidak mudah untuk ditembus dan lebih mudah dalam pengaksesannya. Karena kelebihannya tersebut maka seharusnya keperluan dan pekerjaan yang masih dilakukan secara manual seharusnya sudah bisa dilakukan secara otomatis (Zhafran, 2017). Salah satu teknologi yang penggunaannya berkembang pesat dalam bidang keamanan adalah Radio Frequency Identification atau biasa disebut RFID (Danta et al., 2016).

RFID adalah teknologi yang mampu mengidentifikasi dan mengambil data dari suatu objek dengan cara otomatis tanpa melibatkan manusia. Cara kerja otomatis RFID menggunakan gelombang elektromagnetik yang dapat mengubah data antara terminal dengan suatu objek (Fika Husna Amalina Mubarok \& Muhammad Subali, 2020). RFID menggunakan gelombang radio untuk identifikasi suatu objek yang dilakukan oleh RFID reader dan RFID transponder (RFID tag). Setiap RFID tag yang dilekatkan pada suatu objek yang akan diidentifikasi memiliki ID Number yang unik (Danta et al., 2016) (Ketut et al., 2017). Ada tiga komponen RFID terdiri dari (Figa et al., 2015):

1. RFID reader yang merupakan alat yang kompatibel dengan tag card RFID yang berkomunikasi secara wireless dengan tag card.

2. RFID tag card (transponder) merupakan alat yang menyimpan informasi untuk mengidentifikasi objek. 
3. Antena yang mentransmisikan sinyal frekuensi radio antara RFID reader dengan RFID tag card.

Menurut (Zhafran, 2017) yang mengutip pernyataan dari Maryono 2005 menyatakan bahwa RFID merupakan teknologi yang penggunaannya sangat mudah selain itu teknologi sangat cocok dengan sistem yang bersifat otomatis. Tag yang terdapat pada RFID digolongkan menjadi dua yaitu RFID aktif dan RFID pasif. RFID aktif adalah RFID yang sumber dayanya dapat diperoleh dari baterai, sedangkan RFID pasif adalah RFID yang sumber dayanya diperoleh dari medan elektromagnetik.

Tujuan dirancangnya alat ini adalah untuk meringankan operator dalam membuka dan menutup portal parkir. Selain itu alat ini bisa mengefisiensikan waktu dengan tidak memerlukan bantuan operator untuk mengakses portal parkir. Teknologi ini juga menggunakan notifikasi yang masuk pada web sederhana yang dapat mengetahui akses pada portal parkir sehingga apabila terjadi pencurian kendaraan maka user akan mudah menelusurinya. Apabila terjadi ketidakcocokan kartu RFID maka buzzer akan berbunyi dan menampilkan notifikasi pada layar LCD.

\section{METODE PENELITIAN}

Penelitian ini diawali dengan studi literatur atau mencari referensi yang telah ada dan berkaitan dengan komponen yang dibutuhkan dalam proses pembuatan prototype sistem keamanan parkir dengan menggunakan RFID. tahap berikutnya yaitu merancang alat yang diawali dengan analisis kebutuhan sistem baik kebutuhan perangkat lunak maupun perangkat keras (Figa et al., 2015). Studi kasus dalam penelitian ini yaitu berlokasi di Universitas Islam Makassar. Adapun objek dalam penelitian ini adalah gerbang pintu masuk dan pintu keluar di Universitas Islam Makassar. Penelitian dilaksanakan pada bulan Juni sampai dengan bulan Agustus 2021.

Alat yang digunakan dalam perancangan prototype sistem keamanan parkir otomatis adalah sebagai berikut :

1. RFID (Radio Frequency Idetification)

2. NodeMCU ESP32

3. LCD $16 \times 2$

4. Motor Servo MG995

5. Buzzer

6. Sensor Ultrasonik HCSR04 
7. Software Arduino IDE

8. Modul I2C

\section{HASIL DAN PEMBAHASAN}

\subsection{Blok Diagram}

Blok diagram digunakan untuk menjelaskan cara kerja suatu sistem secara keseluruhan yang menggambarkan suatu blok dengan blok lain yang saling berhubungan dan berkaitan. Selain itu blok diagram juga penting dalam merancang suatu sistem (Fika Husna Amalina Mubarok \& Muhammad Subali, 2020).

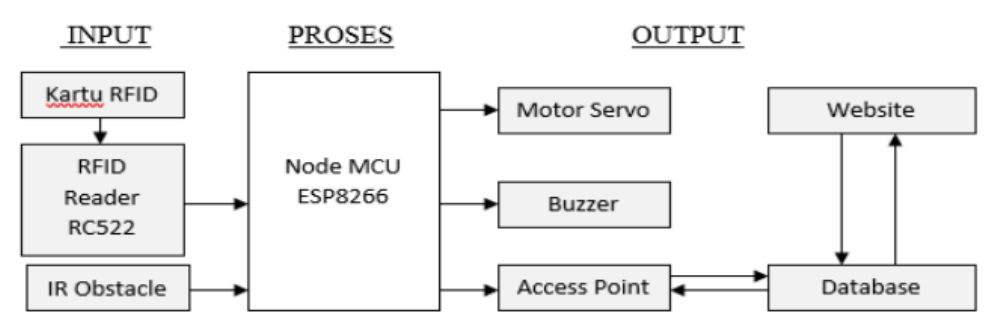

Gambar 1: Blok Diagram

\subsection{Blok Input}

Pada blok input ini digunakan 2 sensor untuk masuk dan keluar parkir yaitu satu buah RFID dan satu buah Sensor Ultrasonik HCR04. Kedua sensor ini mempengaruhi proses dan output sistem. Kedua sensor ini memberikan sinyal input kemudian NodeMCU memproses input tersebut kemudian diteruskan kedatabase dan website. Blok ini juga membaca perintah dari reader lalu Reader RFID akan membaca. setelah Reader RFID membaca inputan maka portal akan terbuka dan selanjutnya sensor Ultrasonik HRC04 akan menutup portal pada saat kendaraan sudah lewat. 


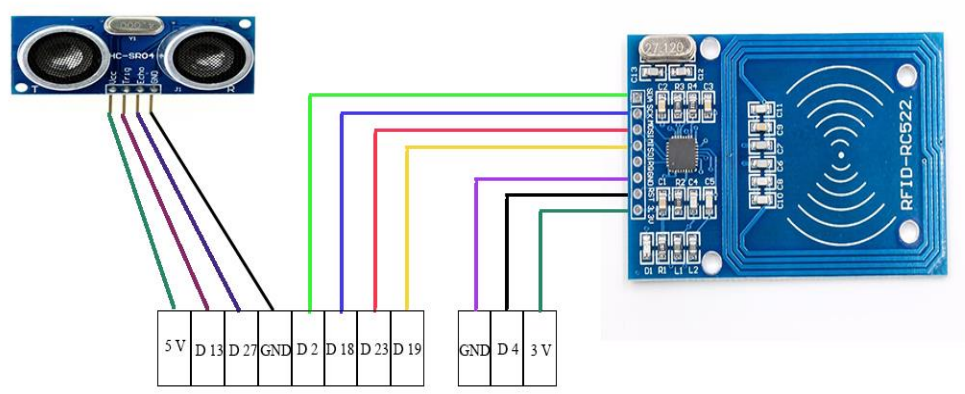

Gambar 2: Blok Input

\subsection{Blok Proses}

Blok proses ini data yang diterima dari tap kartu RFID akan diproses oleh RFID Reader. selanjutnya NodeMCu ESP32 membaca data yang telah terdaftar atau yang belum terdaftar jika kartu terdaftar maka secara otomatis portal parkir akan terbuka sebaliknya jika data belum terdaftar maka akan muncul notifikasi pada website bahwa data tidak terdaftar dan portal tidak akan terbuka. kemudian sensor Ultrasonik HRC04 berfungsi untuk membaca adanya kendaraan yang lewat dan ketika kendaraan telah lewat, maka portal akan tertutup secara otomatis.

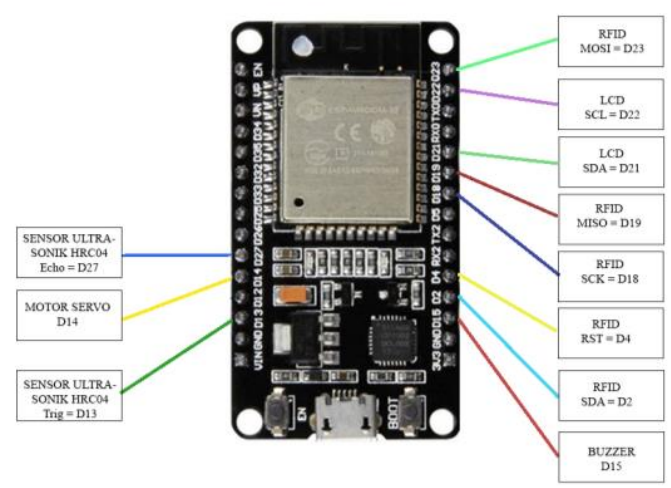

Gambar 3: Blok Proses

\subsection{Blok Output}

Proses pada blok output yaitu kartu RFID yang ditempelkan pada RFID reader sudah terdaftar maka motor Servo akan bergerak 90 derajat dan secara otomatis pintu portal akan terbuka dan sensor Ultrasonik HRC04 akan menutup kembali jika kendaraan telah melewati portal. dan apabila kartu tidak terdaftar dalam sistem maka buzzer 
akan berbunyi dan menampilkan notifikasi pada layar LCD yang memebritahukan bahwa kartu belum terdaftar.

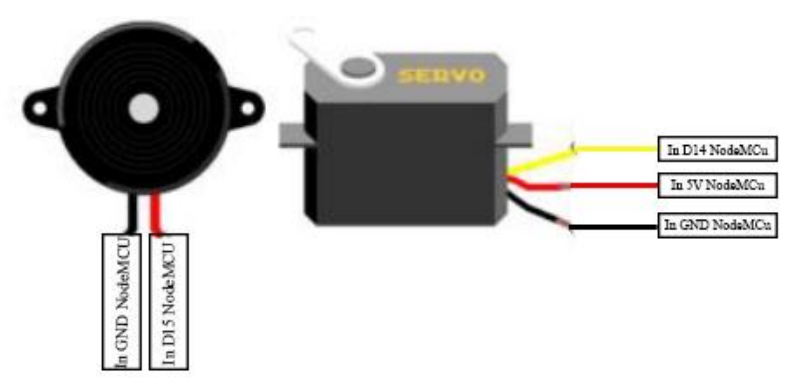

Gambar 4: Blok Output

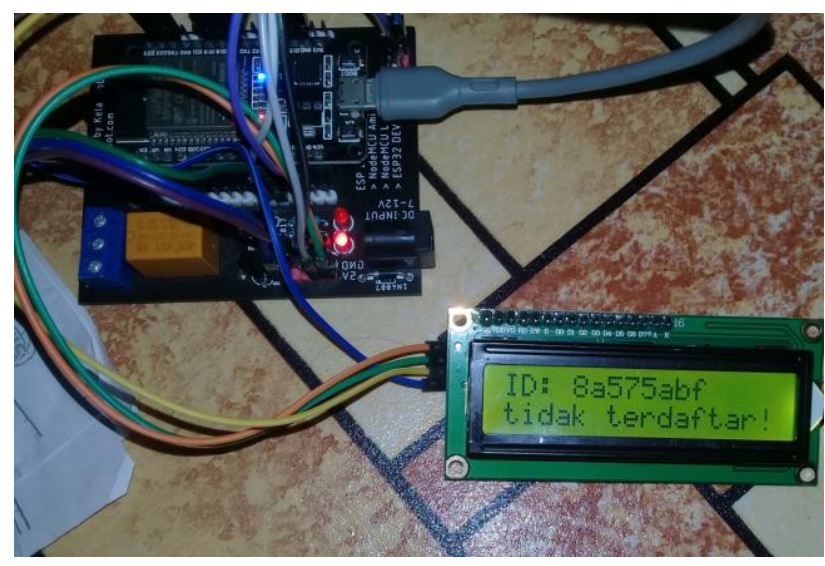

Gambar 5: Blok Output

\subsection{Rangkaian Sistem Secara Keseluruhan}

Perangkat pengirim dan perangkat penerima dalam sistem parkir otomatis ini harus saling terhubung. Komponen mikrokontroler NodeMCU ESP32 dengan komputer selain harus terhubung dengan sumber tegangan juga harus terhubung dengan jaringan yang ama. Alamat IP yang digunakan untuk internet harus sesuai dengan alamat IP yang diubah dalam kode program NodeMCU ESP32. 


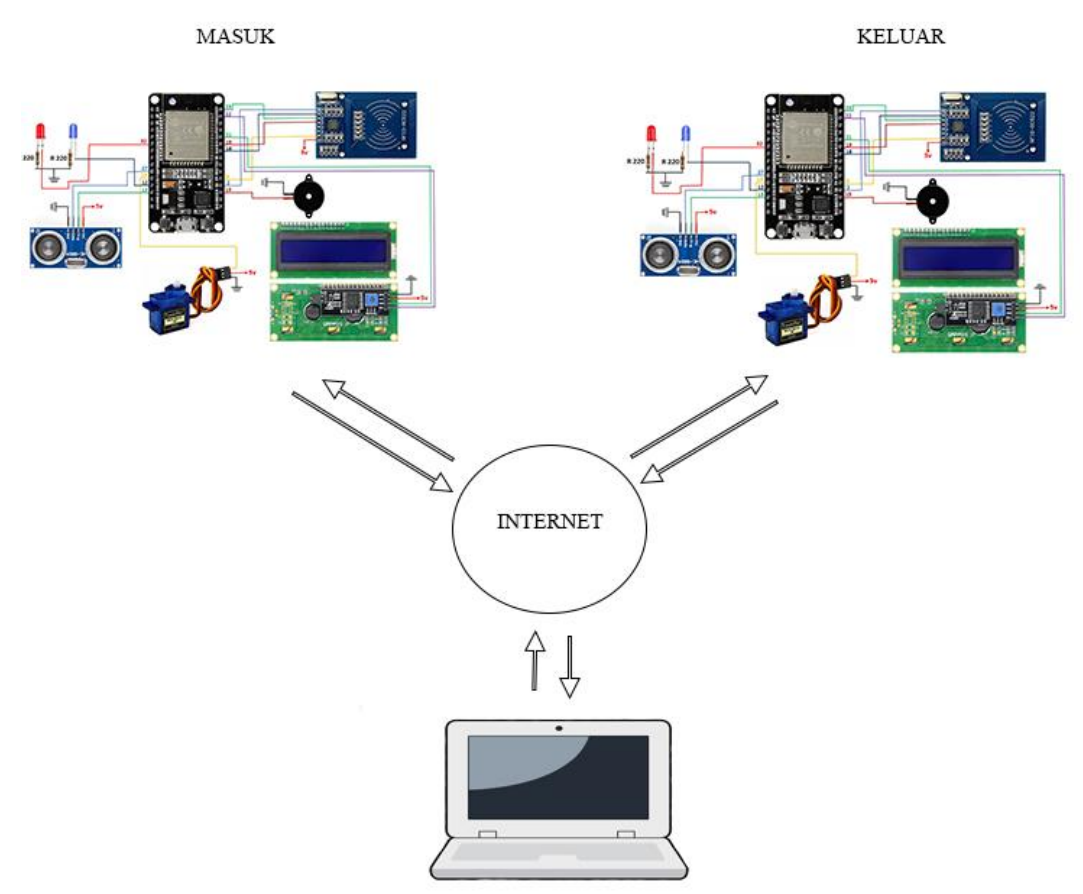

Gambar 6: Rangkaian Sistem Secara Keseluruhan

Rangkaian ini menggunakan Radio Frequency Identation ( RFID ) yang terhubung ke mikrokontroler NodeMCU ESP32, yaitu RST dihubungkan ke pin D4 pada kode program, SDA dihubungkan ke pin D2 pada kode program, SCK dihubungkan ke pin D18 pada kode program, MISO dihubungkan ke pin D19 pada kode program, MOSI dihubungkan ke pin D23, GND kita hubungkan GND ke NodeMCU, 3.3 V dihubungkan ke $3 \mathrm{~V}$ pada NodeMCU. Dan juga ada Ultrasonik HRC04 dimana memakai Pin ECHO sensor ultrasonik HRC04 dihubungkan ke pin D27 NodeMCU ESP32, pin TRIGGER sensor ultrasonik HRC04 dihubungkan ke pin D13 NodeMCU ESP32, pin GND sensor ultrasonik HRC04 dihubungkan ke pin GND NodeMCU ESP32, dan pin 5v sensor ultrasonik HRC04 dihubungkan ke pin VCC NodeMCU ESP32 pada kode program. Pada Motor servo PWM dihubungkan ke pin D14 NodeMCU ESP32, GND dihubungkan ke GND NodeMCU ESP32 dan 5 V dihubungkan ke VCC pada NodeMCU ESP32. Dan pada Buzzer masukkan pin positif (+) dihubungkan ke pin D15 NodeMCU ESP32 dan pin negatif (-) buzzer dihubungkan pada GND pada NodeMCU ESP32. Pada LCD SDA dihubungkan ke pin D21 NodeMCU ESP32, SCL dihubungkan 
ke pin D22 NodeMCU ESP32, GND dihubungkan ke GND NodeMCU ESP32 dan 5 V dihubungkan ke VCC pada NodeMCU ESP32.

\section{SIMPULAN}

Pemanfaatan teknologi RFID dalam perancangan Prototype sistem parkir otomatis adalah untuk mengidentifikasi kendaraan maupun user yang keluar masuk ke Universitas Islam Makassar. Jika Tag RFID terdaftar dalam database maka tag tersebut merupakan tag kendaraan civitas akademika Universitas Islam Makassar. penggunaan teknologi ini diharapkan dapat meminimalisir tindakan pencurian kendaraan khususnya kendaraan roda dua.

\section{DAFTAR PUSTAKA}

Danta, B. M., Sentinuwo, S. R., \& Putro, M. D. (2016). Implementasi Teknologi Radio Frequency Identification untuk Identifikasi dan Autentikasi pada Gerbang Masuk diUniversitas Sam Ratulangi Manado. Jurnal Teknik Informatika, 9(1). https://doi.org/10.35793/jti.9.1.2016.13458

Figa, U., Dedi, T., \& Yulrio, B. (2015). Prototype Sistem Keamanan Pintu Menggunakan Radio Frequency Identification (Rfid) Dengan Kata Sandi Berbasis Mikrokontroler. Jurnal Coding, Sistem Komputer Untan, 03(1), 30-40.

Fika Husna Amalina Mubarok, \& Muhammad Subali. (2020). SISTEM KEAMANAN PINTU PORTAL PADA PERUMAHAN DENGAN RFID MENGGUNAKAN NODEMCU. Seminar Nasional Teknologi Informasi Dan Komunikasi (SeNTIK), 4, 311-321.

Ketut, N., Dharmi, H., \& Andreawan, S. (2017). Perancangan Prototipe Pintu Gerbang UNJANI Keluar Masuk Kendaraan Menggunakan RFID Berbasis Mikrokontroler ATmega32. Seminar Nasional Microwave Antena Dan Propagasi (SMAP), Desemberr, 204-207.

Uray Ristian, Weldi, D. T. (2020). APLIKASI SISTEM KONTROL PORTAL PARKIR MENGGUNAKAN METODE LOCK GPS BERBASIS INTERNET OF THINGS (Studi Kasus: Lahan Parkir Masjid Raya Mujahidin Pontianak). Coding Jurnal Komputer Dan Aplikasi, 8(3), 40. https://doi.org/10.26418/coding.v8i3.42956

Zhafran, A. A. haidar. (2017). SISTEM AKSES MASUK RBTE BERBASIS RFID. 